\title{
KESIAPAN SUMBER DAYA PENGAWAS PLTN DI INDONESIA
}

\author{
Aris Sanyoto $^{1}$ dan Eko Legowo ${ }^{2}$ \\ ${ }^{1}$ Balai Diklat - Badan Pengawas Tenaga Nuklir \\ ${ }^{2}$ Biro Umum - Badan Pengawas Tenaga Nuklir \\ Jalan Gajah Mada No. 8, Jakarta Pusat
}

\begin{abstract}
ABSTRAK
KESIAPAN SUMBER DAYA PENGAWAS PLTN DI INDONESIA. Rencana pembangunan PLTN di Indonesia memperoleh tanggapan beragam dari masyarakat, salah satunya penolakan. Salah satu alasan penolakan adalah kekawatiran terhadap kemampuan sumber daya dan kompetensi sumber daya manusia (SDM) yang akan mengelolanya. Untuk menjawab kekawatiran tersebut, maka dibutuhkan sebuah badan pengawas yang memadai yang mampu memastikan terpenuhinya semua persyaratan yang dibutuhkan untuk mengoperasikan PLTN secara aman dan selamat. Menurut IAEA Safety Guide No. GS-G-1.1, supaya memadai sebagai Badan Pengawas, BAPETEN harus memiliki kemandirian sumber daya yang meliputi berbagai aspek seperti politik, legislatif, financial, informasi public, internasional dan kompetensi. Hasil analisa menunjukkan bahwa organisasi BAPETEN telah memiliki kemandirian sumber daya seperti rekomendasi IAEA. Kemandirian dari aspek politik dapat dilihat dari Undang-Undang No. 10 Tahun 1997 tentang Ketenaganukliran, dimana kedudukan BAPETEN langsung di bawah Presiden Republik Indonesia, sedangkan kemandirian dari aspek legislatif yaitu struktur organisasi BAPETEN telah memiliki fungsi-fungsi yang dibutuhkan dalam proses pengawasan seperti fungsi pengembangan regulasi dan pedoman, fungsi review \& penilaian, fungsi perijinan dan inspeksi, fungsi riset dan pengembangan, fungsi penanggulanan kedaruratan dan fungsi hubungan internasional. Selanjutnya supaya BAPETEN dapat melaksanakan fungsifungsi pengawasan secara memadai maka harus memiliki technical expertise meliputi kerangka kompetensi seperti yang direkomendasikan IAEA dalam tecdoc 1254.. Hasil analisa terhadap silabus program pelatihan SDM BAPETEN menunjukkan bahwa jenis-jenis kompetensi yang direkomendasikan IAEA sebagian besar sudah terakomodir dalam program pelatihan. Namun demikian untuk memastikan level kompetensi yang sudah dimiliki SDM BAPETEN, khususnya 262 yang memiliki kualifikasi pendidikan teknik, perlu dilakukan penilaian melalui proses Training Needs Assessment (TNA). Hasil dari proses ini akan memberi gambaran mengenai gap (kesenjangan) antara level kompetensi standar dan kompetensi yang sudah ada (existing).
\end{abstract}

Kata kunci: pengawasan, PLTN, personil, SDM, TNA

\section{ABSTRACT}

THE PREPARATION OF REGULATORY RESOURCES TO CONTROL THE NPP IN INDONESIA. There are many responses of public in line with the planning to develop nuclear power plant (NPP) in Indonesia; one of them is rejecting it. One of the reasons is worry on the resources as well as the competency of human resources who will operate it. To overcome this situation, therefore it is necessary presence of regulatory authority with capabilities to ensure all requirements to operate the NPP safely and securely. According to the IAEA Safety Guide No GS-G-1.1, in order to have capabilities as regulatory authority, BAPETEN shall have independence resources covering some aspects, such as political, legislative, financial, public information, international, and competency. The independence from the political aspects can be observed from the Act number 10 Year 1997 on Nuclear energy, where BAPETEN's organization is directly responsible to President of Republic of Indonesia, meanwhile the independence from legislative aspect where some function such as regulation and guide development, review and assessment, licensing, inspection, research \& development, emergency response preparedness and international communication has been covered in its organization structure. Moreover, in order to do its function appropriately, BAPETEN shall own technical expertise as recommended by IAEA Tecdoc 1254. Identification of training syllabus, most of the competency has been addressed in the BAPETEN's training program. However, to 
assess the competency level of every BAPETEN's personnel, especially those 262 with technical education background, it is necessary to do a training need assessment (TNA) process. The result of the process will figure out the gap between the required and existing competency.

Keywords : regulatory, NPP, personnel, resources, TNA.

\section{PENDAHULUAN}

Rencana pembangunan PLTN di Indonesia memperoleh tanggapan beragam dari masyarakat, salah satunya penolakan. Salah satu alasan penolakan adalah kekawatiran terhadap kemampuan sumber daya dan kompetensi sumber daya manusia (SDM) yang akan mengelola dan mengawasinya. Untuk menjawab kekawatiran tersebut, maka dibutuhkan sebuah badan pengawas yang mampu memastikan terpenuhinya semua persyaratan yang dibutuhkan untuk mengoperasikan PLTN secara aman dan selamat.

Supaya Badan Pengawas Tenaga Nuklir (BAPETEN) mampu memastikan terpenuhinya semua persyaratan yang dibutuhkan dalam pengoperasian PLTN secara aman dan selamat, maka harus didukung dengan sumber daya dan SDM yang memadai.

Tujuan dari makalah ini adalah untuk menganalisa sumber daya dan SDM yang dimiliki BAPETEN yang dibutuhkan untuk mengawasi rencana pembangunan PLTN menggunakan standar IAEA.

\section{IAEA Safety Guide No. GS-G-1.1}

Menurut rekomendasi IAEA Safety Guide No. GS-G-1.1. Organization and Staffing of the Regulatory Body for Nuclear Facilities, Badan Pengawas harus memiliki struktur sedemikian rupa untuk menjamin kemampuannya dalam menjalankan tanggung-jawabnya dan didukung dengan sumber daya manusia (SDM) yang berkompeten ${ }^{[1]}$. Supaya badan ini mampu melaksanakan tugasnya secara efektif dan efisien maka harus memiliki kemandirian-kemandirian (sumber daya) yang mencakup beberapa aspek, seperti kemandirian aspek politik, aspek legislatif, aspek financial, aspek kompetensi, aspek informasi publik dan aspek internasional. Selain itu, badan ini harus didukung dengan fungsi-fungsi yang diperlukan untuk mengawasi instalasi nuklir, termasuk Pembangkit Listrik Tenaga Nuklir (PLTN) ${ }^{1}$. Adapun fungsifungsi tersebut adalah fungsi pengembangan regulasi dan pedoman, fungsi review \& penilaian, fungsi perijinan dan fungsi inspeksi \& penegakan hukum. Selain fungsi-fungsi tersebut, fungsi lain yang diperlukan meliputi fungsi kesiapsiagaan kedaruratan, fungsi informasi publik, fungsi pemantau radioaktivitas di dalam \& di luar instalasi, fungsi pendukung administrative, fungsi bantuan hukum, fungsi komite penasehat, fungsi riset dan pengembangan dan fungsi hubungan internasional.

Adapun efektivitas pengawasan yang dilakukan Badan Pengawas memerlukan serangkaian kompetensi untuk setiap satuan fungsi organisasi atau unit kerja. Kerangka kompetensi sumber daya manusia (SDM) yang dibutuhkan untuk setiap fungsi berbeda-beda. Kompetensi tersebut merupakan kombinasi dari beberapa unsur, yaitu unsur Pengetahuan (Knowledge), Keterampilan (Skill) dan Perilaku (Attitude). Menurut dokumen teknis publikasi IAEA Training the Staff of Regulatory Body for Nuclear Facilities: A Competency Framework ${ }^{[2]}$, kompetensi tersebut dijabarkan ke dalam 4 (empat) kuadran. Kuadran 1: Kompetensi Dasar Hukum dan Proses Pengawasan; meliputi kompetensi dasar hukum, kompetensi proses pengawasan, kompetensi dokumen pengawasan, kompetensi dokumen izin dan proses perijinan dan kompetensi proses penegakan hukum. Kuadran 2: Kompetensi Terkait dengan Disiplin Teknis; meliputi kompetensi teknologi dasar, kompetensi teknologi terapan dan kompetensi teknologi spesialis. Kuadran 3: Kompetensi Penyelenggaraan Pengawasan; meliputi kompetensi teknik analisa berfokus keselamatan, kompetensi teknik inspeksi, kompetensi teknik audit dan kompetensi teknik investigasi, sedangkan Kuadran 4: Kompetensi Efektivitas Personal dan Interpersonal; meliputi kompetensi analisis dan penyelesaian masalah, kompetensi pengambilan keputusan, teknologi informasi, organisasi \& manajemen diri, kompetensi komunikasi, kompetensi kerjasama dan kompetensi teamwork.

\section{Struktur Organisasi BAPETEN}

Struktur organisasi ditunjukkan pada Gambar 1. Penjelasan:

\section{Deputi Bidang Perijinan dan Inspeksi (Deputi PI)}

a. Direktorat Perijinan Fasilitas Radiasi dan Zat Radioaktif (DPFRZR)

b. Direktorat Perijinan Instalasi dan Bahan Nuklir (DPIBN)

c. Direktorat Inspeksi Fasilitas Radiasi dan Zat Radioaktif (DIFRZR)

d. Direktorat Inspeksi Instalasi dan Bahan Nuklir (DI2BN)

Subdirektorat Evaluasi Dosis dan Lingkungan

e. Direktorat Keteknikan dan Kesiapsiagaan 


\section{Nuklir (DKKN)}

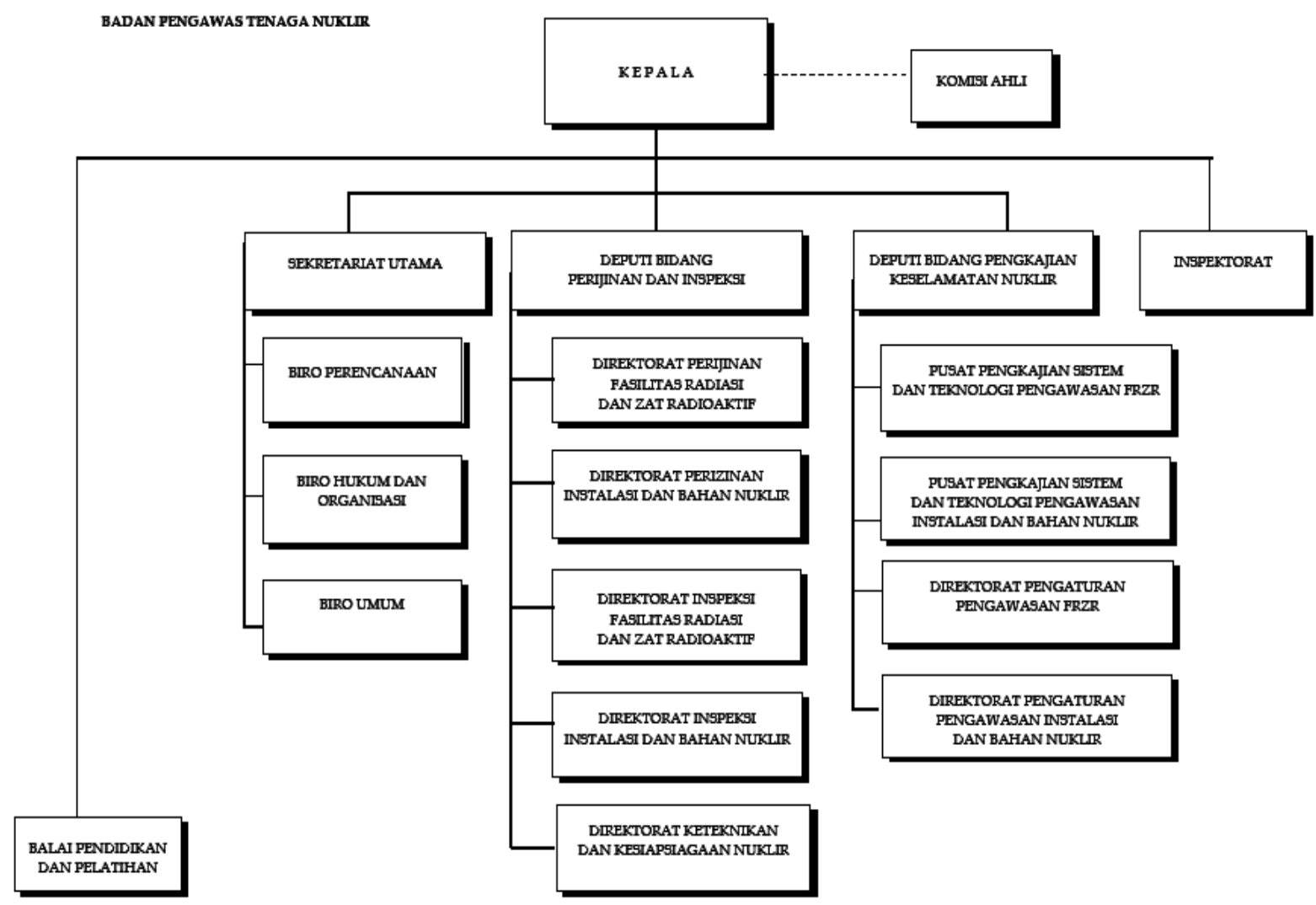

Gambar 1. Struktur Organisasi BAPETEN

(Menurut Perka No. 11 Tahun 2008)

\section{Deputi Bidang Pengkajian Keselamatan Nuklir} (Deputi PKN)

a. Pusat Pengkajian Sistem dan Teknologi Pengawasan FRZR (P2STPFRZR)

b. Pusat Pengkajian Sistem dan Teknologi Pengawasan Instalasi dan Bahan Nuklir (P2STPIBN)

c. Direktorat Pengaturan Pengawasan FRZR (DP2FRZR)

d. Direktorat Pengaturan Pengawasan Instalasi dan Bahan Nuklir (DP2IBN)

\section{Sekretariat Utama}

a. Biro Perencanaan (BP)

Bagian Kerjasama (Dalam dan Luar Negeri)

b. Biro Hukum dan Organisasi (BHO)

Bagian Hukum

Bagian Hubungan Masyarakat dan Protokol

c. Biro Umum (BU)

\section{Unit Kerja Lainnya}

a. Balai Pendidikan dan Pelatihan (BDL)

b. Inspektorat

\section{Gambaran SDM BAPETEN}

Gambaran SDM BAPETEN menurut pendidikan per 29 Agustur 2010 ditunjukkan pada Tabel 1. 
Tabel 1. Gambaran SDM Menurut Pendidikan (Per 29 Agustus 2010)

\begin{tabular}{|c|c|c|c|c|}
\hline \multirow[t]{2}{*}{ NO. } & \multirow[t]{2}{*}{ LEVEL } & \multicolumn{2}{|c|}{ KELOMPOK } & \multirow[t]{2}{*}{ TOTAL } \\
\hline & & TEKNIK & NON TEKNIK & \\
\hline 1 & D3 & 25 & 20 & 45 \\
\hline 2 & D4 & 11 & 0 & 11 \\
\hline 3 & $\mathrm{~S} 1$ & 160 & 88 & 248 \\
\hline 4 & $\mathrm{~S} 2$ & 56 & 19 & 75 \\
\hline 5 & S3 & 10 & 0 & 10 \\
\hline \multicolumn{2}{|c|}{ TOTAL } & 262 & 127 & 389 \\
\hline
\end{tabular}

\section{Program Pengembangan SDM}

\section{Kerangka Pelatihan SDM IN}

a. Orientasi Pegawai (induksi) b. Proteksi Radiasi Teknis (PR)

c. Jabatan Fungsional Pengawas Radiasi (JabFung)

d. BPTC-IN \& BPTC-FRZR

e. Inspektur

f. Reaktor Daya (RD)

g. Reaktor Non Daya (RND)

h. Instalasi Nuklir Non Reaktor (INNR)

i. $\quad$ Proteksi Fisik (PF)

j. Nond Destructive Analysis (NDA)

k. SSAC

1. Kedaruratan Nuklir $(\mathrm{KN})$

m. OJT Reaktor (OJT)

n. Lainnya (Seminar, Workshop, dl)

\section{Kerangka Pengembangan Kompetensi}

Kerangka ditunjukkan pada Tabel 2.

Tabel 2. Jenis Kompetensi Pengawasan PLTN Vs Silabus Pelatihan

\begin{tabular}{|c|c|c|c|c|c|c|c|c|c|c|c|c|c|c|}
\hline JENIS KOMPETENSI & & & & & $\begin{array}{r}\mathrm{CAl} \\
\mathrm{K}\end{array}$ & 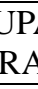 & & A & SI & $\begin{array}{l}\mathrm{BL} \\
\mathrm{AN}\end{array}$ & & & & \\
\hline Kuadran 1 & $\mathrm{a}$ & $\mathrm{b}$ & $\mathrm{c}$ & d & $\mathrm{e}$ & $\mathrm{f}$ & $\mathrm{g}$ & $\mathrm{h}$ & $\mathrm{i}$ & $\mathrm{j}$ & $\mathrm{k}$ & 1 & $\mathrm{~m}$ & $\mathrm{n}$ \\
\hline Dasar hukum & $\checkmark$ & $\checkmark$ & $\checkmark$ & $\checkmark$ & $\checkmark$ & - & - & - & - & - & - & - & - & $\checkmark$ \\
\hline Proses pengawasan & $\checkmark$ & $\checkmark$ & $\checkmark$ & - & $\checkmark$ & - & - & - & - & - & - & $\checkmark$ & - & $\checkmark$ \\
\hline Dokumen pengawasan & - & - & $\checkmark$ & - & $\checkmark$ & - & - & - & - & - & - & - & - & - \\
\hline $\begin{array}{l}\text { Dokumen izin \& } \\
\text { proses perijinan }\end{array}$ & - & - & $\checkmark$ & - & $\checkmark$ & - & - & - & - & - & - & - & - & - \\
\hline $\begin{array}{l}\text { Proses penegakan } \\
\text { hukum. }\end{array}$ & - & - & - & - & $\checkmark$ & - & - & - & - & - & - & - & - & $\checkmark$ \\
\hline Kuadran 2 & & & & & & & & & & & & & & \\
\hline Teknologi dasar & - & - & - & - & - & - & - & - & - & - & - & - & - & - \\
\hline Teknologi terapan & - & $\checkmark$ & - & $\checkmark$ & $\checkmark$ & $\checkmark$ & $\checkmark$ & $\checkmark$ & $\checkmark$ & $\checkmark$ & $\checkmark$ & $\checkmark$ & $\checkmark$ & - \\
\hline $\begin{array}{l}\text { Teknologi spesialis } \\
\text { Kuadran } 3\end{array}$ & - & - & - & - & - & $\checkmark$ & $\checkmark$ & $\checkmark$ & $\checkmark$ & $\checkmark$ & $\checkmark$ & - & $\checkmark$ & - \\
\hline $\begin{array}{l}\text { Teknik analisa } \\
\text { fokus keselamatan }\end{array}$ & - & - & - & - & $\checkmark$ & - & - & - & - & - & - & - & - & - \\
\hline Teknik inspeksi & - & - & - & - & $\checkmark$ & - & - & - & - & - & - & - & - & - \\
\hline Teknik audit & - & - & - & - & - & - & - & - & - & - & - & - & - & - \\
\hline $\begin{array}{l}\text { Teknik investigasi } \\
\text { Kuadran } 4\end{array}$ & - & - & - & - & $\checkmark$ & - & - & - & - & - & - & $\checkmark$ & - & - \\
\hline $\begin{array}{l}\text { Analisis dan } \\
\text { penyelesaian masalah }\end{array}$ & - & - & - & - & $\checkmark$ & - & - & - & - & - & - & - & - & - \\
\hline Pengambilan keputusan & - & - & - & - & $\checkmark$ & - & - & - & - & - & - & - & - & - \\
\hline $\begin{array}{l}\text { Teknologi informasi } \\
\text { \& Komunikasi }\end{array}$ & - & - & - & - & - & - & - & - & - & - & - & $\checkmark$ & - & - \\
\hline $\begin{array}{l}\text { Organisasi \& } \\
\text { manajemen diri }\end{array}$ & - & - & - & - & $\checkmark$ & - & - & - & - & - & - & - & - & - \\
\hline $\begin{array}{l}\text { Kerjasama } \\
\text { dan teamwork. }\end{array}$ & - & - & - & - & - & - & - & - & - & - & - & - & - & - \\
\hline
\end{tabular}

\section{PENGOLAHAN DATA DAN} PEMBAHASAN

Undang-undang No. 10 Tahun 1997 tentang
Ketenaganukliran secara jelas memberi amanat kepada Badan Pengawas untuk menjamin keselamatan dan kesehatan pekerja, anggota masyarakat dan perlindungan lingkungan hidup 
terhadap segala kegiatan pemanfaatan tenaga nuklir (Pasal 15). Pada tanggal 8 Mei 1998, melalui Keputusan Presiden Republik Indonesia No. 76 Tahun 1998 tentang Badan Pengawas Tenaga Nuklir, pemerintah membentuk Badan Pengawas Tenaga Nuklir (BAPETEN) sebagai Badan Pengawas ketenaganukliran. Menurut rekomendasi IAEA, supaya badan ini mampu melaksanakan tugasnya maka harus memiliki kemandirian sumber daya yang mencakup beberapa aspek, meliputi aspek politik, aspek legislatif, aspek financial, aspek informasi public, aspek internasional dan aspek kompetensi. $^{[1]}$

Kemandirian dari aspek politik. Dalam Undang-undang No. 10 tahun 1997 telah secara tegas dinyatakan bahwa organisasi BAPETEN sebagai badan pengawas terpisah dari organisasi yang mempromosikan penggunaan tenaga nuklir di Indonesia (BATAN). Dalam pasal 4 undang-undang ini dinyatakan bahwa badan pengawas (BAPETEN) secara langsung bertanggung-jawab kepada Presiden Republik Indonesia. Aspek ini sangat penting terkait netralitas dan obyektivitas dalam pengambilan keputusan yang terkait dengan keselamatan.

Kemandirian dari aspek legislative. Organisasi BAPETEN dibentuk melalui Keputusan Presiden Republik Indonesia No. 76 Tahun 1998 tentang Badan Pengawas Tenaga Nuklir tanggal 19 Mei 1998, Organisasi ini memiliki fungsi sebagai satu-satunya pengawas ketenaganukliran di Indonesia (Pasal 2). Untuk melaksanakan fungsi pengawasan maka BAPETEN didukung dengan struktur organisasi seperti terlihat pada Gambar 1. Struktur Organisasi BAPETEN. Struktur tersebut sebagian besar telah mengikuti rekomendasi IAEA yang meliputi beberapa fungsi, seperti fungsi pengembangan regulasi dan pedoman, fungsi review \& penilaian, fungsi perijinan dan inspeksi \& penegakan hokum, fungsi kesiapsiagaan kedaruratan, fungsi informasi publik, fungsi pemantau radioaktivitas di dalam \& di luar instalasi, fungsi pendukung administratif, fungsi bantuan hukum, fungsi komite penasehat, fungsi riset dan pengembangan dan fungsi hubungan internasional [1]. Semua fungsi-fungsi tersebut berada dalam level eselon 2 (dua). Beberapa fungsi yang tidak terlihat secara jelas dalam struktur organisasi, karena berada di bawah eselon dua, adalah fungsi hubungan internasional, fungsi informasi public, fungsi pemantau radioaktivitas dan fungsi bantuan hukum. Fungsi hubungan internasional berada di bawah kepala Biro Perencanaan, fungsi informasi public dan fungsi bantuan hokum berada di bawah Biro Hukum dan Organisasi dan fungsi pemantauan radioaktivitas berada di bawah Direktorat Inspeksi Instalasi dan Bahan Nuklir (DI2BN).

Kemandirian aspek financial. Supaya memiliki kewenangan dan power yang memadai,
BAPETEN memiliki anggaran mandiri. Anggaran ini sangat penting untuk dapat melaksanakan proses pengawasan secara obyektif.

Kemandirian aspek informasi publik. Kemandirian ini diperlukan oleh BAPETEN untuk berkomunikasi kepada publik mengenai persyaratan pengawasan, keputusan dan opini yang dibuat. Publik akan memiliki kepercayaan kepada BAPETEN apabila semua proses pengaturan dan pengambilan keputusan dilakukan secara transparan.

Kemandirian aspek internasional. Untuk mempromosikan kerjamasama dan pertukaran informasi pengawasan, BAPETEN memiliki otoritas untuk bekerjasama dengan badan pengawas dari negara-negara lain dan juga dengan organisasi internasional, seperti IAEA, dll.

Kemandirian aspek kompetensi. Supaya dapat melakukan pengawasan secara profesional dan mandiri, BAPETEN harus memiliki technical expertise pada kerangka kompetensi seperti yang direkomendasikan IAEA dalam tecdoc 1254. ${ }^{[2]}$. Saat SDM BAPETEN dengan kualifikasi pendidikan D3, D4, S1, S2 dan S3 berjumlah 389, dimana 262 diantaranya memiliki kualifikasi teknik. Supaya SDM BAPETEN memiliki kompetensi yang memadai dan senantiasa terpelihara, maka SDM tersebut harus mengikuti pelatihan yang telah diagendakan dalam Program Pelatihan. Dari Tabel 2. Jenis Kompetensi Pengawasan PLTN Vs Silabus Pelatihan, terlihat bahwa hampir semua kerangka kompetensi yang direkomendasikan IAEA melalui Tecdoc 1254 telah tercakup dalam silabus kerangka pelatihan SDM BAPETEN. Dari Tabel tersebut juga terlihat bahwa jenis kompetensi yang tidak ada dalam silabus pelatihan adalah kompetensi teknologi dasar (Kuadran 2), kompetensi teknik audit (Kuadran 3) dan kompetensi Kerjasama/ teamwork (Kuadran 4). Kompetensi teknologi dasar tidak diagendakan di dalam silabus pelatihan karena kompetensi tersebut diasumsikan sudah diperoleh pada jenjang pendidikan formal. Termasuk dalam kompetensi teknologi dasar adalah disiplin ilmu teknik nuklir, fisika nuklir, teknik kimia, ilmu bahan, ilmu matematika, teknik sipil, teknik mesin, ilmu kebumian, teknik lingkungan, ilmu computer, teknik listrik, dll. Sedangkan kompetensi kerjasama/ teamwork belum masuk ke dalam silabus salah satu program pelatihan sehingga kompetensi ini perlu diakomodir dalam satu jenis pelatihan yang lain.

Dari Tabel 2 tersebut juga dapat dielaborasi, bahwa terdapat beberapa jenis kompetensi yang memperoleh porsi sedikit dalam silabus pelatihan sehingga perlu diperhatikan. Adapun jenis kompetensi tersebut adalah kompetensi proses penegakan hukum (Kuadran 1), kompetensi teknik analisa berfokus keselamatan, kompetensi teknik inspeksi dan kompetensi teknik investigasi (Kuadran 3) dan kompetensi analisis dan 
penyelesaian masalah, kompetensi pengambilan keputusan, kompetens organisasi \& manajemen diri, kompetensi teknologi informasi \& komunikasi, kompetensi kerjasama dan teamwork (Kuadran 4). Idealnya, setelah mengikuti pelatihanpelatihan yang telah ditetapkan dalam kerangka pelatihan tersebut, SDM BAPETEN akan memiliki kompetensi yang diperlukan untuk memastikan semua persyaratan pengoperasian PLTN secara aman dan seamat. Namun demikian untuk memastikan level kompetensi yang sudah dimiliki SDM BAPETEN, IAEA melalui publikasi Tecdoc 1254 merekomendasikan untuk melakukan penilaian melalui proses Training Needs Assessment (TNA). Hasil dari proses ini akan memberi gambaran mengenai gap (kesenjangan) antara level kompetensi standar (yang seharusnya dimiliki) dan kompetensi yang sudah ada (existing). Gambaran gap kompetensi ini akan sangat berguna untuk menyusun program pengembangan SDM yang sesuai untuk masing-masing personil BAPETEN

\section{KESIMPULAN}

Dari analisa data dapat disimpulkan hal-hal sebagaiberikut:

1. Badan Pengawas Tenaga Nuklir (BAPETEN) telah memiliki kemandirian sumber daya yang dibutuhkan untuk mengawasi rencana pembangunan PLTN di Indonesia.
2. Kerangka kompetensi yang dibutuhkan untuk memastikan semua persyaratan pengoperasian PLTN secara aman dan selamat, sebagian besar telah terakomodir dalam program pelatihan SDM BAPETEN.

3. Untuk memastikan level kompetensi yang sudah dimiliki SDM BAPETEN, khususnya 262 SDM yang memiliki kualifikasi teknik, perlu dilakukan penilaian melalui proses Training Needs Assessment (TNA).

\section{DAFTAR PUSTAKA}

1. IAEA, "Organization and Staffing of the Regulatory Body for Nuclear Facilities”, Safety Guide No. GS-G-1.1, IAEA, Vienna, 2002

2. IAEA, Tecdoc 1254: Training the Staff of Regulatory Body for Nuclear Facilities: A Competency Framework, IAEA, Vienna, 2001

3. Undang-undang No. 10 Tahun 1997 tentang Ketenaganukliran

4. Keputusan Presiden Republik Indonesia No. 76 Tahun 1998 tentang Badan Pengawas Tenaga Nuklir tanggal 19 Mei 1998;

5. Peraturan Kepala BAPETEN No. 11 Tahun 2008 tentang Perubahan atas Keputusan Kepala Badan Pengawas Tenaga Nuklir No. 01 rev.2/K-OTK/V-04 tentang Organisasi dan Tata Kerja Badan Pengawas Tenaga Nuklir 